\title{
Perceived usefulness and ease of use of fundoscopy by medical students: a randomised crossover trial of six technologies (eFOCUS 1)
}

\author{
H. P. Dunn ${ }^{1,2^{*}}$, C. J. Kang ${ }^{1}$, S. Marks' ${ }^{1}$, J. L. Witherow ${ }^{3}$, S. M. Dunn ${ }^{1}$, P. R. Healey ${ }^{1,2,4}$ and A. J. White ${ }^{1,2,4}$
}

\begin{abstract}
Background: Fundoscopy outside ophthalmology is in decline, and the technical demands of the traditional direct ophthalmoscope examination are likely contributing. Alternative fundoscopy technologies are increasingly available, yet valid comparisons between fundoscopy technologies are lacking. We aimed to assess medical students' perceptions of usefulness and ease of use of traditional and contemporary fundus-viewing technologies including smartphone fundoscopy.

Methods: One hundred forty-six second-year medical students participated in a cross-sectional, randomised, crossover study of fundoscopy methods. Medical students completed small group training sessions using six current fundoscopy technologies including: a non-mydriatic fundus camera; two types of direct fundoscopy; and three types of smartphone fundoscopy. A novel survey of perceived usefulness and ease of use was then completed by students.

Results: Repeated-measures ANOVA found students rated both the perceived usefulness $(p<0.001)$ and ease of use $(p<0.001)$ of smartphone fundoscopy significantly higher than both the non-mydriatic camera and direct fundoscopy.

Conclusions: Smartphone fundoscopy was found to be significantly more useful and easier to use than other modalities. Educators should optimise student access to novel fundoscopy technologies such as smartphone fundoscopy which may mitigate the technical challenges of fundoscopy and reinvigorate use of this valuable clinical examination.
\end{abstract}

Keywords: Fundoscopy, Smartphone, Education, Non mydriatic camera, Direct ophthalmoscope

\section{Background}

Fundoscopy remains one of the great teaching challenges despite being a core skill for clinicians [1, 2], recognised by the International Council of Ophthalmology as one of

\footnotetext{
* Correspondence: hamish.dunn@sydney.edu.au

${ }^{1}$ Faculty of Medicine \& Health, University of Sydney, Sydney, Australia 2Department of Ophthalmology, Westmead Hospital, Sydney, Australia Full list of author information is available at the end of the article
}

seven basic ophthalmic medical education competencies [3]. Fundoscopy offers a non-invasive view of the central nervous system, revealing clinical signs of raised intracranial pressure $[4,5]$, end-organ damage from hypertension and diabetes $[6,7]$ and even the risk of stroke $[8$, 9]. Despite the clinical benefits of fundoscopy for patients, it is infrequently performed in routine clinical practice across community internists [10], hospital physicians [11], emergency physicians [12] and even

(c) The Author(s). 2021 Open Access This article is licensed under a Creative Commons Attribution 4.0 International License, which permits use, sharing, adaptation, distribution and reproduction in any medium or format, as long as you give appropriate credit to the original author(s) and the source, provide a link to the Creative Commons licence, and indicate if changes were made. The images or other third party material in this article are included in the article's Creative Commons licence, unless indicated otherwise in a credit line to the material. If material is not included in the article's Creative Commons licence and your intended use is not permitted by statutory regulation or exceeds the permitted use, you will need to obtain permission directly from the copyright holder. To view a copy of this licence, visit http://creativecommons.org/licenses/by/4.0/ The Creative Commons Public Domain Dedication waiver (http://creativecommons.org/publicdomain/zero/1.0/) applies to the data made available in this article, unless otherwise stated in a credit line to the data. 
neurologists [13]. Current fundoscopy practice is not only infrequent but poorly reliable. Bruce et al. found that $13 \%$ of ED patients who warranted fundoscopy had acute life or vision-threatening fundus pathology, yet none of these findings were identified by emergency physicians using the traditional direct ophthalmoscope (TDO) [12].

While current clinical practice is limited by the shortcomings of TDO, novel fundus imaging technologies offer a potential solution. The changed optics of the panoptic ophthalmoscope offer a wider field of view than the TDO, probably contributing to higher diagnostic accuracy in some studies [14-16]. Fundus photography is closer to the gold standard of dilated expert examination than TDO $[17,18]$. Where novel technologies create a digital fundus image, the difficulties of interpreting findings may be mitigated [19] by the ability to modify, review and transmit the fundus image. Technological improvements to fundus imaging utilising the ubiquitous smartphone could improve device availability [20-22] alongside reduced technical barriers, and have shown similar diagnostic accuracy to fundus photography in some studies [23]. In the era of COVID-19 social distancing, the physical proximity of patient and clinician when using the TDO is potentially hazardous to both [24]. Despite the burgeoning availability of fundusviewing technologies [25] and fundoscopy simulators, there is a paucity of comparative effectiveness studies [26] and a lack of validated tools for comparing their performance.

The present decline in fundoscopy has been attributed to technical difficulties in performing traditional ophthalmoscopy, compounded by the challenge of interpreting clinical findings [27]. From the perspective of doctors choosing to examine the fundus or not, these causes align respectively with perceived ease of use (PEOU) and perceived usefulness (PU), as described in the Technology Acceptance Model [28]. Perceived ease of use and usefulness have been repeatedly shown to predict future use of technologies [28-31], and underlie attitudes and behaviours towards health technology [32-35]. If fundoscopy is easier to perform and interpret, uptake by medical students and clinicians will likely improve. This should lead to better patient outcomes, so long as future studies concurrently demonstrate acceptable diagnostic accuracy of novel fundoscopy devices.

In this study we aimed to develop a survey of perceived ease of use and usefulness relevant to fundoscopy; and to measure these factors for commercially available fundoscopy technologies. We hypothesised that perceived ease of use and usefulness would be significantly different between technologies, and that smartphone fundoscopy would outperform TDO.

\section{Methods}

This study adhered to the Declaration of Helsinki and Ethics Committee approval was obtained. Written informed consent was obtained from participants.

\section{Study design \\ Cross-sectional, randomised, cross-over study.}

\section{Setting \& participants}

343 second-year medical students from the University of Sydney undertaking a mandatory ophthalmology training day at the Sydney Eye Hospital were offered study participation. No prior practical or theoretical ophthalmic teaching was conducted in their degree.

\section{Educational intervention and fundoscopy devices}

Training started with a 20-min eye anatomy and examination talk with a video overview of TDO technique. Students were asked to have one pupil dilated with tropicamide $0.5 \%$ to facilitate fundus examination. All 343 students were randomised into groups of 12-16 students using a computer-generated random number given out on arrival. Each group commenced with a different 10min station to avoid any learning bias from the order of instruction, and rotated through six stations: (1) NMC with combined ocular coherence tomography [Topcon, 3D OCT-1 Maestro, Tokyo, Japan]; (2) coaxial traditional direct ophthalmoscope (TDO) [Welch Allyn, Macquarie Park, NSW, Australia]; (3) Panoptic Ophthalmoscope [Welch Allyn, Macquarie Park, NSW, Australia], and; smartphone fundoscopy with (4) Panoptic + iExaminer [Welch Allyn, Macquarie Park, NSW, Australia]; (5) D-eye [Padova, Italy]; and (6) a prototype smartphone adaptor each attached to an iPhone 5 or 6 [Apple Inc., Cupertino, CA, USA] (see Additional file 1 for device characteristics). An ophthalmologist and a technical assistant were present at each station providing standardised device instructions and assistance if required. Students then examined each other with each device.

\section{Survey development}

Davis et al's 12-item PU \& PEOU survey [28] was modified for application to medical devices, with a target population of medical students and doctors. The survey was used for content validity and the original six domains were adapted for both PEOU and PU [36]. Candidate questions were then optimised via independent verification by the authors and three non-participant medical students, to generate the final wording (Table 1). The authors had diverse backgrounds in medicine (HD, CK, SD, AW, PH), ophthalmology (HD, AW, PH), psychology and qualitative research (HD, SD), and biomedical and computer engineering (SM). A 5-point 
Table 1 6-item survey of usefulness and ease of use showing the original constructs and the final modified wording

\begin{tabular}{lll}
\hline Scale items & Original construct & Modified wording \\
\hline Usefulness & Work more quickly & Using the device in my clinical placements would enable me to accomplish tasks more quickly \\
$\mathbf{1}$ & Job performance & Using the device would improve my clinical performance \\
$\mathbf{3}$ & Increase productivity & Using the device in my clinical placement would increase my productivity \\
$\mathbf{4}$ & Effectiveness & Using the device would enhance my effectiveness \\
$\mathbf{5}$ & Makes job easier & Using the device would make it easier to do my clinical placements \\
$\mathbf{6}$ & Useful & I would find the device useful in my clinical placements \\
Ease of Use & & \\
$\mathbf{1}$ & Easy to learn & Learning to operate the device would be easy for me \\
$\mathbf{2}$ & Controllable & I would find it easy to get the device to do what I want it to do \\
$\mathbf{3}$ & Clear \& understandable & My interaction with the device would be straightforward \\
$\mathbf{4}$ & Flexible & I would find the device to be flexible to use in different clinical scenarios \\
$\mathbf{5}$ & Easy to become skillful & It would be easy for me to become skillful at using the device \\
$\mathbf{6}$ & Easy to use & I would find the device easy to use \\
\hline
\end{tabular}

Likert scale was used from 1 = 'Unlikely' to 5 = 'Likely', yielding a score range of 6 to 30 for usefulness and PEOU.

In order to maximise response rates, questionnaire length was streamlined [37] and fundoscopy technologies were grouped as shown below:

1. Non-Mydriatic Camera (NMC);

2. Direct fundoscopy comprising TDO and Panoptic, and;

3. Smartphone fundoscopy comprising D-Eye and iExaminer.

The prototype was excluded as it was in early development and not commercially available.

\section{Survey}

After each station students rated: the quality of training; their perceived ease of viewing the fundus; and confidence with the equipment. At the end of the training day, students were also asked to score the modalities of fundoscopy according to PU and PEOU; and how frequently they would examine the fundus during future general examinations (see Additional file 2).

\section{Outcomes}

The primary outcomes were the perceived usefulness and ease of use scores for the technology groups. Secondary outcomes included confidence to view the fundus, and self-reported future fundoscopy practice patterns.

\section{Analysis}

Statistical analysis was performed using SPSS (version 15.0; SPSS Inc., Chicago, IL). Continuous data were reported as mean and $95 \%$ confidence interval (CI), and categorical data as percentages. Statistical significance was set at $\alpha=0.05$. Survey scores for different fundoscopy technologies were examined using one-way repeated measures analysis of variance (ANOVA) and post-hoc comparisons performed with Bonferroni correction. Analysis of each survey question included results from participants with complete data, who recorded scores for all relevant fundoscopy technologies. Internal consistency of the items assessing PU and PEOU surveys was calculated using Cronbach's alpha. Internal consistency of a psychometric score is generally rated well if the Cronbach alpha is between 0.7 and 0.95 [38].

\section{Results}

\section{Baseline characteristics}

Four training sessions were held over 2 days in May 2017 with a total of 343 students, of whom 146 completed the survey (43\% response rate). The median age was 24 (IQR 22-26) and 78 (53\%) were women. This was similar to the entire cohort amongst whom $47 \%$ were female $\left(x^{2}=1.473, \mathrm{df}=1, p=0.22\right)$. Twelve participants $(8 \%)$ had some previous ophthalmology or optometry training. All 146 participants (100\%) owned a smartphone.

Perceived usefulness scores were significantly different between different fundoscopy modalities (repeated-measures ANOVA $N=100$, F $(2,198)=8.90, p<0.001)$. Posthoc pairwise comparisons showed SF was significantly more useful compared to NMC or direct fundoscopy 
( $p<0.001$ and $p=0.006$ respectively) (Fig. 1 ). There was no significant difference between NMC and direct fundoscopy.

Similarly, PEOU scores were significantly different between different fundoscopy modalities (repeated-measures ANOVA with Huynh-Feldt correction, $N=93$, F (2, $184)=16.865, p<0.001)$. Post-hoc pairwise comparisons showed SF was rated significantly easier to use than NMC $(p<0.001)$ or direct fundoscopy $(p<0.001)$ (Fig. 2). There was no significant difference between NMC and direct fundoscopy $(p=0.207)$.

The modified PUF and PEOU scores were found to have strong internal consistency. Analysis for the PUF scores for NMC, direct fundoscopy and SF found a Crohnbach's alpha of $0.91,0.93$ and 0.91 respectively. The Crohnbach's alpha for the PEOU scores for NMC, direct fundoscopy and SF were 0.94, 0.95 and 0.94 respectively.

There were no observed interaction effects of participants' age, gender, previous ophthalmic training on PEOU or PUF scores (repeated-measures ANOVA, all $p>0.05$ ).

Scores for ease of viewing the fundus were significantly different between modalities (repeated measures ANOVA with Greenhouse- Geisser correction, $N=76$, F $(3.6375)=12.70, p<0.001)$. Post-hoc pairwise comparisons showed students found viewing the fundus significantly harder with the TDO than all modalities (all $p<$ $0.007)$ except the prototype $(p=0.092)$. However, there were no significant differences between any other modalities (see Fig. 3).

Scores for confidence to view the fundus were also significantly different between modalities (repeated measures ANOVA with Greenhouse- Geisser correction, $N=$ 80 , F $(3.7292)=4.70, p=0.002)$. Post-hoc testing found students were significantly less confident using the TDO than the Panoptic $(p=0.001)$ and less confident with the TDO than the D-eye but this result did not reach significance (mean difference $-0.375, p=0.054$ ). Students were more confident using the Panoptic than the prototype $(p=0.019)$. There were no significant differences between NMC, Panoptic and the other smartphone modalities (DE and iE) (Fig. 4).

There was no difference in the perceived quality of training between modalities (one-way ANOVA $N=85, \mathrm{~F}$ $(2,15)=1.50, p=0.19)$. Eighty-five participants (58\%) stated that they would perform fundoscopy as a regular part of their general examination if not asked to do so by their supervisor.

\section{Discussion}

This is the first study to develop validated measures of perceived ease of use and usefulness for fundoscopy. The results support our hypothesis that medical students perceive smartphone fundoscopy to be significantly more useful and easier to use than direct ophthalmoscopy. Furthermore, students found viewing the fundus significantly more difficult using the traditional direct ophthalmoscope than all other commercial technologies.

\section{Perceived ease of use}

Medical student curricula are currently so crowded that little time is offered to ophthalmic training [39], and less still to the complex skill of fundoscopy. Fundoscopy technologies should therefore be as easy to operate as possible. We demonstrated that smartphone fundoscopy was significantly easier to use than direct fundoscopy or NMC $(p<0.001)$. Furthermore, students found viewing the fundus significantly harder with a TDO than any other commercial modality $(p=0.002)$. Whilst other

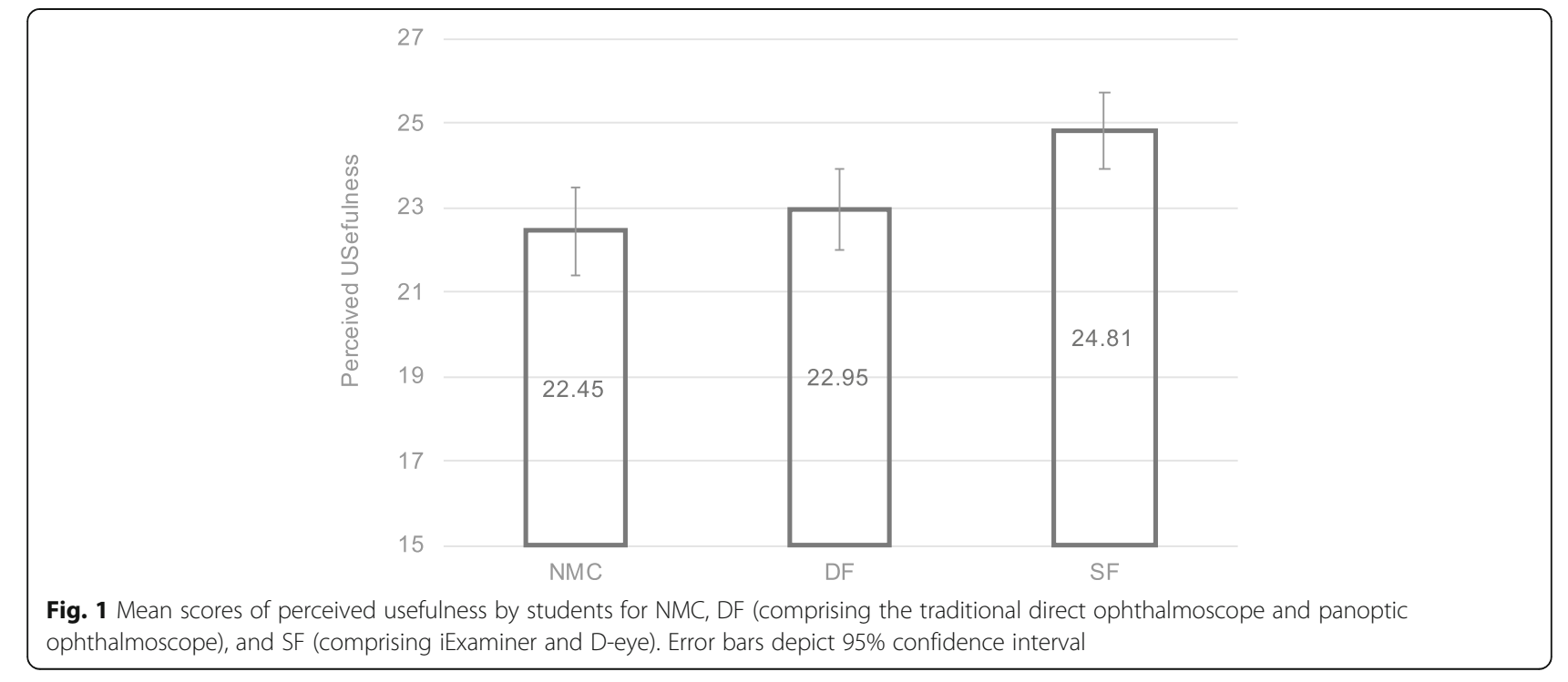




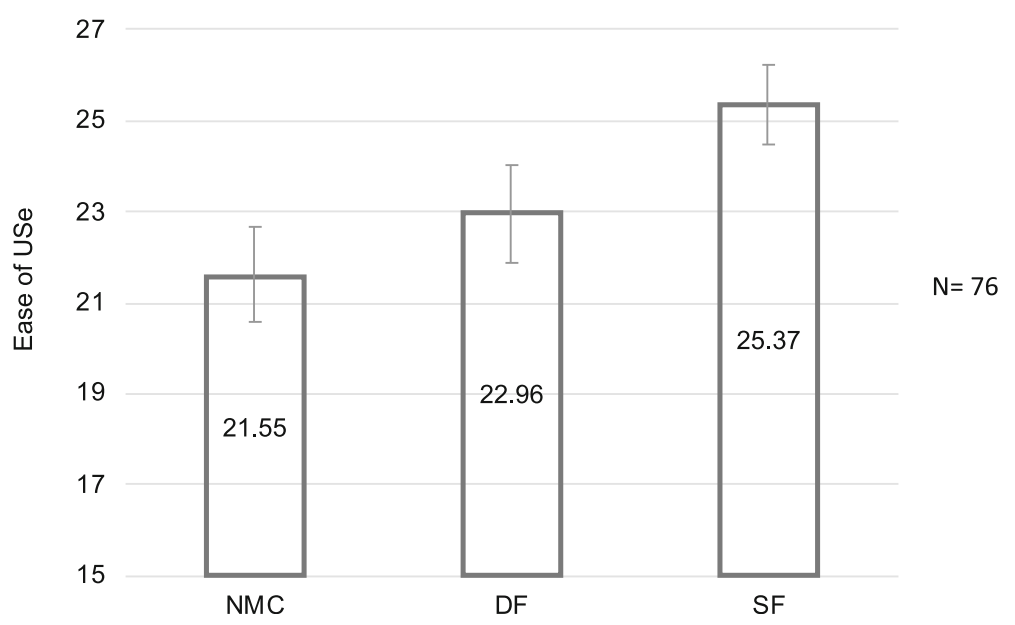

Fig. 2 Mean scores of perceived ease of use by students for non-mydriatic camera (NMC), direct fundoscopy (DF, comprising the traditional direct ophthalmoscope and panoptic ophthalmoscope), and smartphone fundoscopy (SF, comprising iExaminer and D-eye). Error bars show 95\% confidence interval

studies which have shown NMC to be easy to use by non-expert operators $[13,40]$, we found no significant differences between the NMC, D-Eye, iExaminer or Panoptic. These latter four devices share some technical advantages over TDO including a wider field of view, less proximity to the patient and the potential to store and review digital images.

The difficulty of using a TDO in our study is consistent with previous literature $[18,41,42]$. A study of 101 medical students conducted after our trial found TDO was harder to use than the smartphone-mounted D-Eye on an unvalidated Likert scale [43]. Mamtora et al. found smartphone fundoscopy improved the accuracy and quality of fundal examinations by medical students when compared with TDO [44]. Mandal and colleagues developed an ease of use score for fundoscopy based on the capacity to identify anatomical details [45], but the methodology for developing this scale was not reported, and no psychometric validation was performed. To our knowledge, our study is the first to report a validated score of ease of use or usefulness for fundoscopy.

\section{Perceived usefulness}

We found that students rated the usefulness of smartphone fundoscopy significantly greater than both NMC and direct fundoscopy (mean scores 24.81, 22.45, 22.95 respectively; $p<0.001$ ). Perceived usefulness consistently modifies new technology usage over time, whereas perceived ease of use appears to have more influence on early uptake $[29,30]$. Correspondingly, the perceived impact of fundoscopy on patient management may drive usage more than ease of use. Hence usefulness is arguably the central factor in changing clinicians' attitudes and behaviour. Indeed, some experts have suggested that medical school curricula should focus on training students to interpret fundus photographs rather than the vagaries of the TDO $[2,46]$. A study of first-year medical students found $70 \%$ preferred fundus photographs over

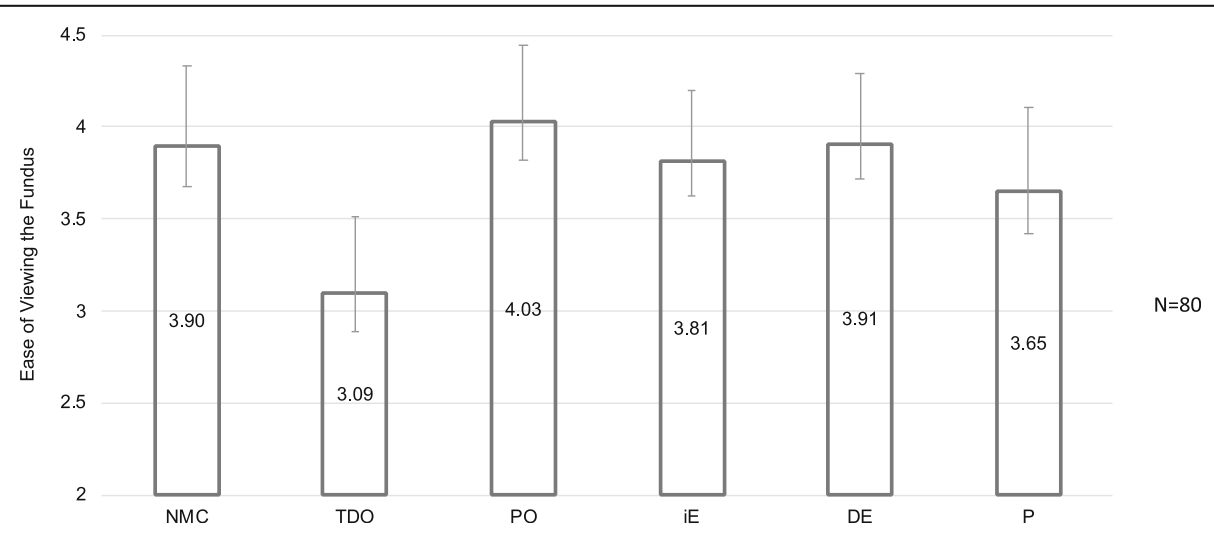

Fig. 3 Mean ease of viewing the fundus by students. (NMC = non-mydriatic camera; TDO = traditional direct ophthalmoscope; PO = Panoptic ophthalmoscope; iE = iExaminer; DE = D-eye; $\mathrm{P}=$ prototype). Error bars depict 95\% confidence interval 
4.5

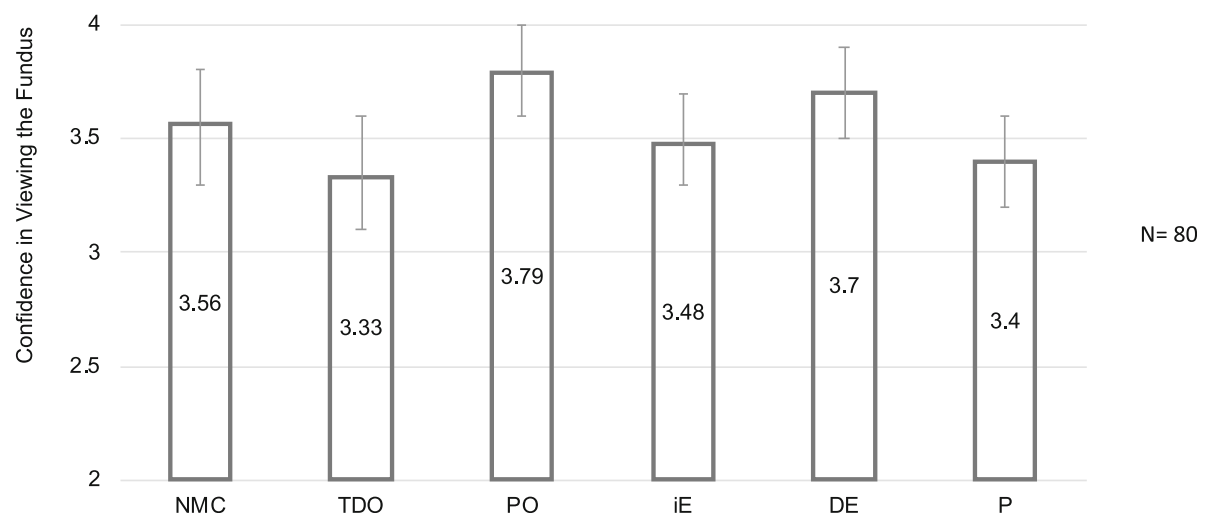

Fig. 4 Mean confidence to view the fundus by students. (NMC = non-mydriatic camera; TDO = traditional direct ophthalmoscope; PO = Panoptic ophthalmoscope; iE = iExaminer; DE = D-eye; $\mathrm{P}=$ prototype). Error bars depict 95\% confidence interval

TDO in clinical practice and were more accurate at diagnosing pathology using photographs [47], with differences sustained after 1 year [41].

Doubtless there are factors beyond perceived usefulness and ease of use which account for fundoscopy practice patterns. However, these two factors consistently account for approximately $40 \%$ of the variance in both intended usage and actual behavior [30], which is greater than any other models of technology use [48]. Moreover, previous educational interventions to improve fundoscopy use which ignored these factors have been largely unsuccessful. Access alone was insufficient, as ownership of a portable direct fundoscopy device did not improve frequency or accuracy of fundoscopy in a randomised controlled trial of 42 students [42]. Retraining students in fundoscopy skills improved diagnostic accuracy but failed to improve the rate of documented fundoscopy in a three-year prospective educational study [49].

The emergence of portable NMCs, telecommunications and smartphone technology have driven an exponential increase in the availability of digital fundus imaging devices [25]. As smartphone fundoscopy image quality improves and NMCs become cheaper and more portable, the clinical usefulness of fundoscopy is likely to increase. A digital fundus image unlocks the capability of telehealth to send the image for specialist advice [50] and increasingly to process the image through artificial intelligence for decision support [51], thus optimising patients' health and the cost-benefit of the examination. For students training in fundoscopy, a digital solution also removes the pressure of time when interpreting findings, limits patient discomfort when reviewing findings, and allows instructors to view and provide feedback on student performance, which is proven to improve results [52]. Many digital fundoscopy modalities, including all commercial devices in this study, have image storage solutions compliant with patient data security requirements. Once the fundus can be reliably visualised, the success of a telehealth intervention still relies on the motivation of physicians to change their clinical practices [53]. Hence, further fundoscopy education is needed to improve the clinical interpretation and implementation of fundus findings.

\section{Confidence}

Limited confidence with fundoscopy examination has been widely reported, and identified as a significant barrier to usage [42, 47, 54]. We found after brief training that medical students were significantly less confident viewing the fundus using the traditional ophthalmoscope $(p=0.001)$ or prototype $(p=0.019)$ than the Panoptic, despite additional instruction for TDO. We found no significant differences in confidence between the novel fundoscopy technologies NMC, D-Eye, iExaminer or Panoptic.

Confidence alone does not predict clinical utility, and perceived usefulness and ease of use are likely better predictors of future fundoscopy practice. Indeed, a study assessing TDO proficiency found students who were incorrect when matching a patient's fundus to a grid of fundus photographs were more confident in their decision than those who were correct [55].

\section{Strengths}

Our study was strengthened by the use of: a proven theoretical framework using the Technology Acceptance Model [30]; a survey validated to predict future use of novel technologies [28] and validated in health contexts [32-35], and; rigorous survey development methodology [38]. This is reflected in the excellent internal 
consistency [38] of the measures of PU and PEOU (Crohnbach alphas 0.91-0.95).

Student groups were randomised to commence with different fundoscopy technologies, thus avoiding any effect of the order of instruction. Our findings appear attributable to factors inherent in the technologies, rather than the instruction methods, as there was no significant difference in perceived training quality, and no interaction effects of participants' age, gender, or previous ophthalmic training on PEOU or PU scores.

\section{Limitations}

Our study has some notable limitations. The response rate was $43 \%$ (146/343), although the known characteristics of our participants were not significantly different to the entire student cohort. Our participants were secondyear medical students with limited clinical experience whose perceptions of usefulness are likely to differ from experienced clinicians. However, perceived ease of use is less likely to be confounded by clinical experience and may therefore have a more general application. This could be tested by future studies exploring perceived ease of use and usefulness amongst experienced clinicians.

Although we found relatively small absolute differences in perceived ease of use and usefulness scores between modalities, the survey we employed has proven strong discriminant validity for distinguishing similar technologies [56].

Aspects of our protocol could have biased students' responses. Students were shown an instructional video for the use of TDO only, which may have increased their capability and comfort with the TDO examination, or anchored their perceptions of appropriate technology for patient examination [57]. Our PEOU and PU scores collated opinions regarding fundoscopy technologies into groups of smartphone fundoscopy, direct fundoscopy and the non-mydriatic camera, in order to assess general distinctions between these groups, and to streamline the length of the survey aiming to improve response rate [37]. However this raises a possible unknown effect of grouping. For example, the TDO and Panoptic were collated under the umbrella term 'direct fundoscopy', yet when surveyed individually the Panoptic outperformed the TDO in all secondary outcomes. Future studies may minimise group confounding by including fewer comparative technologies and representing each individually within the survey.

Whilst our study showed that medical students perceived smartphone fundoscopy as more useful and easier to use than the TDO or a non-mydriatic camera, we did not compare their diagnostic accuracy when using these tools. Further comparative studies will be required to avoid the possibility that an easy to use device may be marred by diagnostic inaccuracy.

\section{Conclusion}

The current clinical practice of fundoscopy is inappropriately infrequent [10-13]. If fundoscopy is easier to perform and interpret, students may find it easier to train and clinicians more likely to perform fundoscopy in clinical practice. Perceived usefulness and ease of use are the best predictors of future technology use [29-31]. Hence we developed the first validated survey of these factors for fundoscopy and compared medical students' perceptions of current fundoscopy technologies. Our findings demonstrate that novel fundoscopy technologies including smartphone fundoscopy are perceived as more useful and easier to use than traditional direct ophthalmoscopy. We suggest that physicians and students should have better access to novel fundoscopy technologies. Further studies will need to compare fundoscopic technologies with regards to diagnostic accuracy, educational outcomes for students, fundoscopy utilisation by clinicians, and ultimately clinical outcomes for patients.

\section{Supplementary Information}

The online version contains supplementary material available at https://doi. org/10.1186/s12909-020-02469-8.

Additional file 1. Characteristics of fundoscopy technologies used in this study. $a=$ details supplied by distributors; $b=$ also requires smartphone; $\mathrm{c}=$ also requires $\mathrm{PO} ; \mathrm{NMC}=$ non-mydriatic camera; $\mathrm{TDO}=$ traditional direct ophthalmoscope; $\mathrm{PO}=$ Panoptic ophthalmoscope; $\mathrm{iE}=$ iExaminer; $D E=D$-eye; $P=$ prototype).

Additional file 2. Student training questionnaire.

\section{Abbreviations}

DE: D-eye; DF: Direct fundoscopy; iE: iExaminer; NMC: Non-mydriatic camera; P: Prototype; PEOU: Perceived ease of use; PO: Panoptic ophthalmoscope PU: Perceived usefulness; SF: Smartphone fundoscopy; TDO: Traditional direct ophthalmoscopy

\section{Acknowledgements}

The authors would like to acknowledge the assistance of the Discipline of Clinical Ophthalmology and Eye Health within the Faculty of Medicine and Health at The University of Sydney for the conduct of this study.

\section{Authors' contributions}

HPD designed the study, arranged ethics approval, collected and analysed the data and drafted the manuscript. CJK collected and analysed the data. SM assisted with study design, data collection and analysis. JLW assisted with study design, data analysis and manuscript drafting. SMD assisted with study design and analysis. PRH and AJW oversaw study design, ethics approval, and data analysis. All authors read, edited for scientific accuracy, and approved the final manuscript.

\section{Funding}

Dr. Hamish Dunn receives a Research Training Program scholarship from the Australian Federal Government (SC1999). Sydney Scientific sponsored in-kind support for an eLearning system developed for follow-up studies eFOCUS 2 and eFOCUS 4. Sydney Scientific also sponsored the device engineering of a prototype smartphone fundoscope used in this study. The sponsor or funding organisations had no role in the design or conduct of this research. 


\section{Availability of data and materials}

The datasets generated and analysed during the current study are available from the corresponding author on reasonable request.

\section{Ethics approval and consent to participate}

This study was approved by the University of Sydney Human Research Ethics Committee on 2nd May 2017. Project no.: 2017/148. Written informed consent was obtained from all participants.

\section{Consent for publication}

Not Applicable

\section{Competing interests}

The Westmead Hospital Dept of Ophthalmology has received research funding for other clinical trials from Hill-Rom/Welch Allyn. Welch-Allyn, TOPCON and Sydney Scientific loaned the training equipment used during this study to the University of Sydney and provided technical assistant staff for the study. The authors have not received any personal funds, and retained independence over the design, analysis and publication of this study.

\section{Author details}

${ }^{1}$ Faculty of Medicine \& Health, University of Sydney, Sydney, Australia. ${ }^{2}$ Department of Ophthalmology, Westmead Hospital, Sydney, Australia. ${ }^{3}$ Discipline of Physiotherapy, Faculty of Medicine \& Health Services, Macquarie University, Sydney, Australia. ${ }^{4}$ Centre for Vision Research, Westmead Institute for Medical Research, University of Sydney, Sydney, Australia.

\section{Received: 8 September 2020 Accepted: 21 December 2020} Published online: 08 January 2021

\section{References}

1. Talley NJ, O'Connor S. Talley \& O'Connor's clinical examination. 8th ed. Chatswood: Elsevier Australia; 2018.

2. Benbassat J, Polak BC, Javitt JC. Objectives of teaching direct ophthalmoscopy to medical students. Acta Ophthalmol $2012 ; 90: 503-507$. https://doi.org/10.1111/j.1755-3768.2011.02221.x..

3. Parrish RK, Tso MOM. Principles and guidelines of a curriculum for ophthalmic education of medical students: Presented by International Task Force on Ophthalmic Education of Medical Students-On behalf of the International Council of Ophthalmology (ICO). Klin Monatsbl Augenheilkd. 2006;223.

4. Jacks AS, Miller NR. Spontaneous retinal venous pulsation: aetiology and significance. J Neurol Neurosurg Psychiatry. 2003;74:7-9.

5. Sinclair AJ, Burdon MA, Nightingale PG, Matthews TD, Jacks A, Lawden M, et al. Rating papilloedema: an evaluation of the Frisen classification in idiopathic intracranial hypertension. J Neurol 2012;259:1406-1412. https:// doi.org/10.1007/s00415-011-6365-6..

6. Klein R, Sharrett AR, Klein BEK, Moss SE, Folsom AR, Wong TY, et al. The association of atherosclerosis, vascular risk factors, and retinopathy in adults with diabetes : the atherosclerosis risk in communities study. Ophthalmology 2002;109:1225-1234. https://doi.org/10.1016/s01616420(02)01074-6..

7. Fraser-Bell S, Symes R, Vaze A. Hypertensive eye disease: a review. Clin Exp Ophthalmol 2017;45:45-53. https://doi.org/10.1111/ceo.12905..

8. Yatsuya H, Folsom AR, Wong TY, Klein R, Klein BEK, Sharrett AR, et al. Retinal microvascular abnormalities and risk of lacunar stroke: atherosclerosis risk in communities study. Stroke 2010;41:1349-1355. https://doi.org/10.1161/ STROKEAHA.110.580837.

9. Wong TY, Klein R, Sharrett AR, Couper DJ, Klein BEK, Liao D-P, et al. Cerebral white matter lesions, retinopathy, and incident clinical stroke. JAMA 2002; 288:67-74. https://doi.org/10.1001/jama.288.1.67..

10. Krane NK, Anderson D, Lazarus CJ, Termini M, Bowdish B, Chauvin S, et al. Physician practice behavior and practice guidelines: using unannounced standardized patients to gather data. J Gen Intern Med 2009;24:53-56. https://doi.org/10.1007/s11606-008-0826-3..

11. Roberts E, Morgan R, King D, Clerkin L. Fundoscopy: a forgotten art? Postgrad Med J. 1999;75:282-4.

12. Bruce BB, Lamirel C, Biousse V, Ward A, Heilpern $\mathrm{KL}$, Newman NJ, et al. Feasibility of nonmydriatic ocular fundus photography in the emergency department: phase I of the FOTO-ED study. Acad Emerg Med 2011;18:928933. https://doi.org/10.1111/j.1553-2712.2011.01147.x..

13. Dalay S, Umar F, Saeed S. Fundoscopy: a reflection upon medical training? Clin Teach 2013;10:103-106. https://doi.org/10.1111/j.1743-498X.2012.00630.x..

14. McComiskie JE, Greer RM, Gole GA. Panoptic versus conventional ophthalmoscope. Clin Exp Ophthalmol 2004;32:238-242. https://doi.org/10. 1111/j.1442-9071.2004.00810.x..

15. Petrushkin H, Barsam A, Mavrakakis M, Parfitt A, Jaye P. Optic disc assessment in the emergency department: a comparative study between the PanOptic and direct ophthalmoscopes. Emerg Med J 2012;29:10071008. https://doi.org/10.1136/emermed-2011-200038..

16. Tan A, Mallika P, Aziz S, Asokumaran T, Intan G, Faridah H. Comparison between the panoptic ophthalmoscope and the conventional direct ophthalmoscope in the detection of sight threatening diabetic retinopathy: the Kuching diabetic eye study. Malays Fam Physician. 2010;5:83-90.

17. Mitchell P, Foran S, Wong TY, Chua B, Patel I, Ojaimi E. NHMRC: Guidelines for the Management of Diabetic Retinopathy. Dep Health Aging. 2008.

18. Harding SP, Broadbent DM, Neoh C, White MC, Vora J. Sensitivity and specificity of photography and direct ophthalmoscopy in screening for sight threatening eye disease: the Liverpool diabetic eye study. BMJ 1995; 311:1131-1135. https://doi.org/10.1136/bmj.311.7013.1131.

19. Li K, He JF. Teaching ophthalmoscopy to medical students (the TOTeMS study). Am J Ophthalmol 2014;157:1328-1329. https://doi.org/10.1016/j.ajo. 2014.02.005..

20. Micheletti JM, Hendrick AM, Khan FN, Ziemer DC, Pasquel FJ. Current and next generation portable screening devices for diabetic retinopathy. J Diabetes Sci Technol 2016;10:295-300. https://doi.org/10.1177/ 1932296816629158.

21. Gavali MY, Khismatrao DS, Gavali YV, Patil KB. Smartphone, the new learning aid amongst medical students. J Clin Diagn Res 2017;11:JC05-JC08. https:// doi.org/10.7860/JCDR/2017/20948.9826.

22. Payne KFB, Wharrad H, Watts K. Smartphone and medical related app use among medical students and junior doctors in the United Kingdom (UK): a regional survey. BMC Med Inform Decis Mak 2012;12:121. https://doi.org/10. 1186/1472-6947-12-121..

23. Adam MK, Brady CJ, Flowers AM, Juhn AT, Hsu J, Garg SJ, et al. Quality and diagnostic utility of mydriatic smartphone photography: the smartphone ophthalmoscopy reliability trial. Ophthalmic Surg Lasers Imaging Retina 2015;46:631-637. https://doi.org/10.3928/23258160-20150610-06..

24. Lai THT, Tang EWH, Chau SKY, Fung KSC, Li KKW. Stepping up infection control measures in ophthalmology during the novel coronavirus outbreak: an experience from Hong Kong. Graefes Arch Clin Exp Ophthalmol. 2020; 258(5):1049-55.

25. Panwar N, Huang P, Lee J, Keane PA, Chuan TS, Richhariya A, et al. Fundus photography in the 21st century--a review of recent technological advances and their implications for worldwide healthcare. Telemed J E Health 2016; 22:198-208. https://doi.org/10.1089/tmj.2015.0068..

26. Ricci LH, Ferraz CA. Ophthalmoscopy simulation: advances in training and practice for medical students and young ophthalmologists. Adv Med Educ Pract 2017:8:435-439. https://doi.org/10.2147/AMEP.S108041..

27. Mackay DD, Garza PS, Bruce BB, Newman NJ, Biousse V. The demise of direct ophthalmoscopy: a modern clinical challenge. Neurol Clin Pract 2015; 5:150-157. https://doi.org/10.1212/CPJ.0000000000000115..

28. Davis FD. Perceived usefulness, perceived ease of use, and user acceptance of information technology. MIS Q 1989;13:319-340. https://doi.org/10.2307/ 249008..

29. Davis FD, Bagozzi RP, Warshaw PR. User acceptance of computer technology: a comparison of two theoretical models. Manag Sci 1989;35: 982-1003. https://doi.org/10.1287/mnsc.35.8.982..

30. Venkatesh V, Davis FD. A theoretical extension of the technology acceptance model: four longitudinal field studies. Manag Sci 2000;46:186204. https://doi.org/10.1287/mnsc.46.2.186.11926..

31. Szajna B. Empirical evaluation of the revised technology acceptance model. Manag Sci 1996;42:85-92. https://doi.org/10.1287/mnsc.42.1.85..

32. Lu H-P, Gustafson DH. An empirical study of perceived usefulness and perceived ease of use on computerized support system use over time. Int J Inf Manag 1994;14:317-329. https://doi.org/10.1016/0268-4012(94)90070-1..

33. Jun GT, Ward J, Clarkson PJ. Systems modelling approaches to the design of safe healthcare delivery: ease of use and usefulness perceived by healthcare workers. Ergonomics 2010;53:829-847. https://doi.org/10.1080/00140139. 2010.489653.. 
34. Schnall R, Higgins T, Brown W, Carballo-Dieguez A, Bakken S. Trust, perceived risk, perceived ease of use and perceived usefulness as factors related to mHealth technology use. Stud Health Technol Inform. 2015;216: 467-71.

35. Claudio D, Velázquez MA, Bravo-Llerena W, Okudan GE, Freivalds A. Perceived usefulness and ease of use of wearable sensor-based systems in emergency departments. IIE Trans Occup Ergon Hum Factors 2015;3:177187. https://doi.org/10.1080/21577323.2015.1040559..

36. Hess TJ, McNab AL, Basoglu KA. Reliability generalization of perceived ease of use, perceived usefulness, and behavioral intentions. MIS Q. 2014;38.

37. Dillman DA, Sinclair MD, Clark JR. Effects of questionnaire length, respondent-friendly design, and a difficult question on response rates for occupant-addressed census mail surveys. Public Opin Q 1993;57:289-304. https://doi.org/10.1086/269376.

38. Terwee CB, Bot SDM, de Boer MR, van der Windt DAWM, Knol DL, Dekker J, et al. Quality criteria were proposed for measurement properties of health status questionnaires. J Clin Epidemiol 2007;60:34-42. https://doi.org/10. 1016/j.jclinepi.2006.03.012..

39. Succar T, Grigg J, Beaver HA, Lee AG. A systematic review of best practices in teaching ophthalmology to medical students. Surv Ophthalmol 2016;61: 83-94. https://doi.org/10.1016/j.survophthal.2015.09.001..

40. Zhang W, Nicholas P, Schuman SG, Allingham MJ, Faridi A, Suthar T, et al. Screening for diabetic retinopathy using a portable, noncontact, nonmydriatic handheld retinal camera. J Diabetes Sci Technol. 2017;11:12834. https://doi.org/10.1177/1932296816658902.

41. Mackay DD, Garza PS, Bruce BB, Bidot S, Graubart EB, Newman NJ, et al. Teaching ophthalmoscopy to medical students (TOTeMS) II: a one-year retention study. Am J Ophthalmol 2014;157:747-748. https://doi.org/10. 1016/j.ajo.2013.12.013..

42. Gilmour-White JA, Picton A, Blaikie A, Denniston AK, Blanch R, Coleman J, et al. Does access to a portable ophthalmoscope improve skill acquisition in direct ophthalmoscopy? A method comparison study in undergraduate medical education BMC Med Educ 2019;19:201. https://doi.org/10.1186/ s12909-019-1644-5..

43. Kim Y, Chao DL. Comparison of smartphone ophthalmoscopy vs conventional direct ophthalmoscopy as a teaching tool for medical students: the COSMOS study. Clin Ophthalmol 2019;13:391-401. https://doi. org/10.2147/OPTH.S190922..

44. Mamtora S, Sandinha MT, Ajith A, Song A, Steel DHW. Smartphone ophthalmoscopy: a potential replacement for the direct ophthalmoscope. Eye. 2018;32:1766-71.

45. Mandal N, Harborne P, Bradley S, Salmon N, Holder R, Denniston AK, et al. Comparison of two ophthalmoscopes for direct ophthalmoscopy. Clin Exp Ophthalmol 2011;39:30-36. https://doi.org/10.1111/j.1442-9071.2010.02403.x.

46. Dos Santos Martins TG, Schor P, de Azevedo Costa AL. Teaching ophthalmoscopy to medical students (the TOTeMS study). Am J Ophthalmol 2014;157:1329-1330. https://doi.org/10.1016/j.ajo.2014.02.047..

47. Kelly LP, Garza PS, Bruce BB, Graubart EB, Newman NJ, Biousse V. Teaching ophthalmoscopy to medical students (the TOTeMS study). Am J Ophthalmol 2013;156:1056-61 e10. https://doi.org/10.1016/j.ajo. 2013.06.022..

48. Legris $P$, Ingham J, Collerette P. Why do people use information technology? A critical review of the technology acceptance model. Inf Manag 2003;40:191-204. https://doi.org/10.1016/S0378-7206(01)00143-4..

49. Mottow-Lippa L, Boker JR, Stephens F. A prospective study of the longitudinal effects of an embedded specialty curriculum on physical examination skills using an ophthalmology model. Acad Med 2009:84:16221630. https://doi.org/10.1097/ACM.0b013e3181bb2d51..

50. Tuckson RVMD, Edmunds M, Hodgkins MLMDMPH. Telehealth. N Engl J Med. 2017:377:1585-92.

51. Besenczi R, Toth J, Hajdu A. A review on automatic analysis techniques for color fundus photographs. Comput Struct Biotechnol J 2016;14:371-384 https://doi.org/10.1016/j.csbj.2016.10.001..

52. Schulz C, Moore J, Hassan D, Tamsett E, Smith CF. Addressing the "forgotten art of fundoscopy": evaluation of a novel teaching ophthalmoscope. Eye 2016;30:375-384. https://doi.org/10.1038/eye.2015.238.

53. Car J, Huckvale K, Hermens H. Telehealth for long term conditions. BMJ 2012;344. https://doi.org/10.1136/bmj.e4201.

54. Gupta RR, Lam WC. Medical students'self-confidence in performing direct ophthalmoscopy in clinical training. Can J Ophthalmol. 2006:41:169-74. https://doi.org/10.1139/106-004.
55. Gilmour G, McKivigan J. Evaluating medical students' proficiency with a handheld ophthalmoscope: a pilot study. Adv Med Educ Pract. 2017;8:33-6. https://doi.org/10.2147/AMEP.S119440.

56. Adams DA, Nelson RR, Todd PA. Perceived usefulness, ease of use, and usage of information technology: a replication. MIS Q. 1992;16:227-47. https://doi.org/10.2307/249577.

57. Tversky A, Kahneman D. Judgment under uncertainty: heuristics and biases. Science. 1974;185:1124-31. https://doi.org/10.1126/science.185.4157.1124.

\section{Publisher's Note}

Springer Nature remains neutral with regard to jurisdictional claims in published maps and institutional affiliations.

\section{Ready to submit your research? Choose BMC and benefit from:}

- fast, convenient online submission

- thorough peer review by experienced researchers in your field

- rapid publication on acceptance

- support for research data, including large and complex data types

- gold Open Access which fosters wider collaboration and increased citations

- maximum visibility for your research: over $100 \mathrm{M}$ website views per year

At BMC, research is always in progress.

Learn more biomedcentral.com/submissions 